NOTICE: this is the author's version of a work that was accepted for publication in Applied Energy. Changes resulting from the publishing process, such as peer review, editing, corrections, structural formatting, and other quality control mechanisms may not be reflected in this document. Changes may have been made to this work since it was submitted for publication. A definitive version was subsequently published in Applied Energy, Vol. 111, (2012). http://dx.doi.org/10.1016/j.apenergy.2013.05.028 


\title{
Modeling Primary Energy Substitution in the Asia Pacific
}

\author{
Roberto F. Aguilera ${ }^{1}$, Ronald D. Ripple ${ }^{2}$
}

\begin{abstract}
A global energy market model (GEM) is used to analyze the market shares (i.e. the primary energy mix) of gases, liquids and solids in the Asia Pacific. The model is successful in matching the historical energy mix from 1850 to 2009. The model also provides a good match of the hydrogen to carbon ratio, which is a proxy for environmental quality. Given these validations, the GEM is then used to present scenarios of the Asia Pacific energy mix and hydrogen to carbon ratio until the year 2030. Three energy mix scenarios are presented - reference case; alternative case 1; alternative case 2 . The reference case assumes limited divergence from current policies and technologies. It indicates that Asia Pacific energy needs will be met by approximately $46 \%$ solids, 34\% liquids, and 20\% gases by 2030. Alternative cases 1 and 2 represent policies and technologies that either encourage or discourage the use of gases. The good matches observed for historical data suggest the GEM can be used cautiously for evaluating outcomes and opportunities in the region. Although the model can be used for projecting far into the future, it is currently calibrated to what we consider a reasonable time horizon - until the year 2030. Given appropriate energy policies and sufficient technological advancement, the importance of natural gas in the region could increase significantly.
\end{abstract}

Keywords: Energy mix; substitution; transitions

\section{Introduction}

The availability of abundant and inexpensive energy sources has been historically linked to the well-being of the global economy. In the Asia Pacific, economic growth has been primarily fueled by coal and oil. As the region continues to grow, natural gas has the potential to play a significant role in satisfying energy demand. Increased use of natural gas will help to reduce dependency on oil and coal, which may result in increased energy security, reduced environmental impact, and continued economic growth [1].

\footnotetext{
${ }^{1}$ Corresponding Author. Centre for Research in Energy and Minerals Economics (CREME), Curtin Business School Curtin University, GPO Box 1987, Perth, Western Australia, 6845, Email: r.aguilera@curtin.edu.au

${ }^{2}$ CREME, Curtin Business School, Curtin University, GPO Box 1987, Perth, Western Australia, 6845, Email: r.ripple@curtin.edu.au
} 
Several obstacles must be overcome in order to reap the benefits from natural gas use. Some of these include limited gas delivery infrastructure, lack of competition and transparency, high transportation costs, lack of storage facilities, underdeveloped and inflexible markets, and limited legal and regulatory frameworks. In addition, some commentators believe there may be a shortage of natural gas resources in the region. To provide insight on the latter, [2] use a Variable Shape Distribution (VSD) model to show that there is no foreseeable shortage of natural gas in the Asia Pacific.

The diamond in Figure 1 represents the framework for this paper. The center of the diamond denotes income and population in the Asia Pacific. ${ }^{3}$ Both are significant determinants of energy consumption and have increased dramatically since 1965. Historical and future energy consumption is shown at the top point of the diamond. Figure 2 corresponds to this point and shows actual primary energy consumption per year in the Asia Pacific [3]. Since 1965, the average annual increase in total energy consumption has been in the order of $10.9 \%$. The lower curve in Figure 2 shows the actual Asia Pacific population from 1965 - 2010 and a forecast to 2030 [4]. This extrapolation produces a figure of approximately five billion people in 2030. With the increase in population comes rapid energy demand growth that results in energy consumption per capita of approximately 80 million BTU by 2030 (middle curve, Figure 2).

Given the estimated energy consumption, the next step is to determine the mix of energy resources that will meet that consumption. The point to the right of the diamond represents the

\footnotetext{
${ }^{3}$ Asia Pacific = Afghanistan, American Samoa, Australia, Bangladesh, Bhutan, Brunei, Cambodia, China, Fiji, French Polynesia, Gilbert-Kiribati, India, Indonesia, Japan, Korea (DPR), Laos, Malaysia, Maldives, Mongolia, Myanmar, Nepal, New Caledonia, New Zealand, Papua New Guinea, Pakistan, Philippines, Republic of Korea, Singapore, Solomon Islands, Sri Lanka, Taiwan, Thailand, Tonga, Vanuatu, Vietnam, Western Samoa
} 
1 historical and future market shares contributed by different primary energy sources. In this paper,

2 the major focus is the modeling of the primary energy mix in the Asia Pacific using a Global

3 Energy Market (GEM) model [5].

4

5 Once the energy mix fractions have been calculated, it is possible to multiply those fractions by

6 the primary energy consumption estimates of Figure 2 in order to obtain consumption rates for

7 specific resources. This step corresponds to the lower point of the diamond. Finally, the question

8 that arises is whether there is sufficient physical availability of primary energy resources to

9 satisfy the consumption rates. This is represented by the left point of the diamond.

\section{Global Energy Market (GEM) Model}

13

14 The GEM model is based on a model of binary technology substitution given by Fisher and Pry

15 [6], later used by [7]:

16

17

$$
\frac{f}{1-f}=\exp (\alpha t+\beta)
$$

20 Where:

$22 f$ is the market share of a competitor;

$23 t$ is time; 
$\alpha$ is a slope parameter;

$2 \quad \beta$ is an intercept parameter;

4 The Fisher and Pry model says that a semilogarithmic plot of $f /(1-f)$ versus $t$ should result in a $5 \quad$ straight line with a slope equal to $\alpha$ and intercept equal to $\beta$. This standard logistic substitution

6 model gives a good match of the historical primary energy mix from 1850 to about 1970 (Figure

7 3). After 1970 , the actual data deviates from the model. This is due to the increased market share 8 of coal in the Asia Pacific after the oil crisis of the 1970s.

9

10 In order to provide a better match of the deviation from linearity, the GEM model was created by

11 introducing additional parameters to the Fisher and Pry equation [5]. To calculate the market

12 fraction of an energy source that is generally declining with time (i.e. downward-sloping), we

13 use the following equation:

14

15

$16 y_{G E M}=\frac{\exp (\alpha t+\beta)}{\psi+(1-\psi)\left[1-\exp \left(\{-\exp (\alpha t+\beta)\} / y_{s}\right)\right]^{S}}=\frac{f}{1-f}$

18 Where:

19

$20 Y_{G E M}$ is the modified function;

$21 \alpha, \beta, t$ and $f$ are defined above for the Fisher and Pry model;

$22 \psi$ represents the approximate point at which a shifted straight line is developed;

$23 y_{s}$ controls the divergence from the straight line; 
$S$ is a severity exponent that controls the slope of the curve that diverges from the straight line;

2

4

In total, there are five parameters $-\alpha, \beta, \psi, y_{s}$, and $S$ - that cause the GEM equation to give the best possible match of the historical energy mix data via non-linear regression (i.e. minimization of the residual sum of squares). Parameters $\alpha$ and $\beta$ are based on the Fisher and Pry model, while $\psi, y_{s}$, and $S$ are unique additions to the GEM model. The parameters are estimated based on visual inspection of the curves, comparison of actual and estimated values, and inspection of the coefficients of determination $\left(\mathrm{R}^{2}\right)$.

For an energy source with a market fraction that is generally increasing with time (i.e. upwardsloping), the numerator in equation 2 must be multiplied by $\psi$. The parameters for the declining and increasing functions are not equal and have to be determined independently for each case.

5

\section{Market Contribution of Solids, Liquids and Gases}

Figure 3 shows the reference case for actual and calculated fractions of the total market given by solids, liquids and gases from 1850 to 2030. The solids-liquids-gases concept was introduced originally by [8]. Solids include wood, agricultural residues (traditional renewables), coal and uranium (nuclear). Liquids include oil and hydropower, while gases include initially methane (i.e. natural gas) and later wind, solar, and hydrogen. Similar combinations are used in this study; however, there are alternate ways of examining the mix. The GEM model, as with the Fisher-Pry model, can also be used to analyze individual energy sources (e.g. coal and uranium, separately) in order to reflect shifts from coal based power to nuclear based power. The same holds true for 
individual liquid or gas sources. However, data limitations exist for certain resources in the Asia

1

Pacific.

The actual energy mix data in Figure 3 is based primarily on [3] and [9]. Data for the post-1965 period comes from [3], which is considered to be a reliable source for primary energy statistics. The pre-1965 data comes from [9], which is based on various sources believed to be reasonably accurate and have been used extensively when analyzing the historical energy mix $[5,7,8,10$, 11, 12]. The various sources used by [9] to synthesize pre-1965 primary energy data are [13], [14], and [15]. The traditional renewables fuel use is based on an extension and revision of earlier estimates made in [16] that only included fuelwood.

The calculated energy mix is obtained with the GEM model, which estimates the parameters that give the best fit of the actual data by minimizing the sum of squared differences between the observed and predicted values. For the case of the solids, the calculated curve was generated using the following parameters: $\alpha=-0.0625, \beta=7.4, \psi=0.02, y_{s}=0.35$ and $S=1.9$. For the case of the gases, the calculated curve was generated with the following parameters: $\alpha=0.0975$, $\beta=15.4, \psi=0.024, y_{s}=3.95$ and $S=1.14 .{ }^{4}$ The liquids curve was obtained by taking the difference between 1.0 and the summation of the solids and gases curves. ${ }^{5}$ In all cases, the comparison between actual and calculated values is good, as confirmed by the coefficients of determination $\left(\mathrm{R}^{2}\right)$ equal to 0.98 . This leads us to conclude that our energy mix scenarios to the

\footnotetext{
${ }^{4}$ While the parameter values do not carry particular economic, policy, or technological meaning, they serve to match the actual historical data and project future scenarios of the energy mix.

${ }^{5}$ Alternative variations of this sequence can also be modeled and will yield similar results (e.g. solids plus liquids, with gases as the residual). However, the chosen pairing simplifies the modeling since the solids and gases fractions are modified linear functions with a negative slope and positive slope, respectively. Thus, specifying these modified linear functions is simpler than specifying a nonlinear bell-shaped equation for the liquids.
} 
year 2030 are reasonable. In addition, our results generally converge to the projections made by other organizations $[17,18]$. The GEM model reference case indicates that by the year 2030, approximately $46 \%$ of primary energy in the Asia Pacific will be provided by solids, $34 \%$ by liquids, and $20 \%$ by gases.

It is important to recognize that a good fit of the past is not necessarily a good indicator of the future. Furthermore, non-uniqueness is an integral part of any history matching process. As a result, we are addressing uncertainties with a couple of alternative cases, as shown in Figures 4 and 5. The alternative cases are generated by varying the values of the three additional GEM parameters $\left(\psi, y_{s}\right.$, and $\left.S\right)$ while maintining a close match of the historical data by not significantly changing the slope and intercept parameters $(\alpha$ and $\beta)$. In the first alternative case (Figure 4) there is a significant increase in the contribution of the solids - and a decrease in the liquids - to the energy mix. The gases share increases very slightly. This could potentially come from government regulations such as price setting that keeps natural gas prices artificially low. These low prices do not provide incentives for companies to invest in the upstream, midstream, or downstream segments of the industry. Increased coal subsidies further hinder the penetration of gas into the market. Government policies in the natural gas sector that limit foreign investment will also inhibit its contribution to the energy mix. In the second alternative case (Figure 5) there is a slight decrease in the contribution of the solids and a slower reduction of the liquids. In this case, the gases share increases significantly. Opportunities to increase gas penetration in the short term would mostly be found in the electricity sector. In the long term, possibilities may also exist in the transport sector. The increases in gas use could come from policies to address climate change, which are likely to favour gas in place of oil and coal. Some of these policies include 
indirect taxes on fuel and costs imposed on carbon emissions. By introducing a substantial cost

2 on carbon, for example, the total cost of coal and gas becomes comparable, in which case

3 relative prices determine the dominant fuel [19]. Presumably this would increase the relative

4 price of coal while encouraging investment in gas, which would lead to technological

5 improvements in gas exploration, production and transportation. This would further induce

6 substitution from coal towards gas by lowering the relative price of gas.

7

8

\section{Consumption Rates}

Using the energy mix fractions presented in the previous section, it is possible to derive annual consumption rates for each energy source. This analysis corresponds to the lower point of the diamond in Figure 1. For the reference case, annual consumption rates are calculated by multiplying total Asia Pacific energy consumption (upper curve in Figure 2) by the market fractions shown in Figure 3. The reference case of the gases, for instance, is given by the middle curve of Figure 6. In 2030, consumption of gases in the region will be around 80 quadrillion BTU (Quads). The lower and upper curves in Figure 6 correspond to the alternative cases presented in Figures 4 and 5 - approximately 50 and 120 Quads, respectively. It is also possible to calculate actual consumption rates of liquids or solids. 


(n)

\section{Availability}

A key concern is whether or not there are sufficient resources to satisfy the consumption rates discussed in the previous section. This corresponds to the left point of the diamond in Figure 1. For the example of natural gas, the answer is positive based on research conducted with a variable shape distribution (VSD) model [2]. The model was validated by successfully comparing calculated and actual natural gas endowment volumes published by the United States Geological Survey (USGS) World Petroleum Assessment 2000 [20].

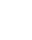

An example of the VSD results, for the case of conventional natural gas, is presented in Figure 7, which shows actual and calculated sizes of gas endowment provinces. According to the USGS, gas endowment refers to the sum of known volumes (cumulative production plus remaining reserves) and undiscovered volumes. The actual gas endowment for the lower curve corresponds to 77 petroleum provinces in the Asia Pacific region that were evaluated by the USGS [20].

Those 77 provinces are natural geological entities, such as sedimentary basins, that were selected for evaluation in [20] since they were thought to contain significant volumes that might be produced over a 30 year time horizon. The total gas endowment estimated by the USGS at 1100 TCF (1134 Quads) compares well with the 1101 TCF (1135 Quads) calculated by the VSD model. The coefficient of determination $\left(\mathrm{R}^{2}\right)$ is equal to 0.99 . Note that these volumes do not include reserve growth or unconventional sources of gas (e.g. tight gas sands, shale gas, coalbed methane). 
Once the model was validated, it was used to estimate the recoverable conventional gas volumes of the 290 provinces recognized to exist in the Asia Pacific, out of which 213 had not been evaluated previously. Significant quantities are also believed to exist in those previously unassessed provinces [21]. The top curve of Figure 7, generated by the VSD model, corresponds to 290 provinces and gives a gas endowment of 1437 TCF (1481 Quads). These results indicate that there are enough recoverable natural gas resources in the Asia Pacific to meet consumption requirements for the next several decades. This should provide sufficient time for the region to shift to other energy sources, perhaps unconventional or non-fossil [22, 23].

\section{Environmental Quality}

The concept of the hydrogen over carbon $(\mathrm{H} / \mathrm{C})$ ratio, which can be used as a proxy for environmental quality, is presented in [12] and [24]. As shown in Figure 8, the GEM model has been used to calculate the Asia Pacific $\mathrm{H} / \mathrm{C}$ ratio. The calculation was carried out using the fractions, from Figures 3 to 5. of solids (wood and coal), liquids and gases and the following average $\mathrm{H} / \mathrm{C}$ ratios: wood $=0.10 ;$ coal $=0.5$; liquids $=2.0$ (assuming mostly oil); and gases $=4.0$ (assuming mostly methane). Each of the ratios was weighted with the actual and GEM-calculated fractional contributions of solids, liquids and gases. Thus, the $\mathrm{H} / \mathrm{C}$ ratio of a particular year is calculated as $(0.10 * \%$ wood $)+(0.5 * \%$ coal $)+(2.0 * \%$ liquids $)+(4.0 * \%$ gases $)$. The middle curve of Figure 8 corresponds to the reference case (from Figure 3), while the lower and upper curves correspond to alternative cases 1 and 2 (from Figures 4 and 5), respectively. 
Figure 8 shows continuous decarbonization from 1900 to 1970 . At this point, the H/C ratio becomes approximately constant. We hypothesize that the flattening of the curve is the result of government interventions such as gas price regulations that lead to decreased natural gas consumption and increased coal consumption $[25,26]$. Such regulations would make the economics of coal production favorable relative to that of natural gas. Alternative case 2 suggests a slight improvement in the $\mathrm{H} / \mathrm{C}$ ratio after the year 2020. This is the result of gases gaining market share in the energy mix. In alternative case 1 , the $\mathrm{H} / \mathrm{C}$ ratio continues to decrease until 2030 as solids maintain their dominance in the energy market.

\section{Conclusions}

A GEM model has been used to assess the past, present and near future of the Asia Pacific energy market. It is successful in matching the historical primary energy mix from 1850 to the present. In addition, the GEM provides a good match of the hydrogen to carbon ratio (which is a proxy for environmental quality) from 1900 to the present. Given that the vast majority of world energy-demand growth will come from the Asia Pacific, the region will play a pivotal role in determining the global energy mix and associated carbon emissions. Thus, policymakers in the region will also have the significant responsibility of facilitating natural gas use and thereby increasing the hydrogen to carbon ratio over time.

\section{Scenarios of the fractional market shares of solids, liquids, and gases to the year 2030 suggest} that the future of gases in the region could be promising, with particular potential for natural gas. Policies would have to be enacted in order to favor capital investment in exploration and 
production, build distribution networks, develop integrated gas markets and easy means of transportation, and create transparent and competitive gas pricing mechanisms.

The GEM results also indicate that there could be potential for solids, but significant technological advances will be required to make these environmentally viable (and safe in the case of uranium/nuclear). In the GEM reference case, approximately $46 \%$ of the energy mix is provided by solids, $34 \%$ by liquids and $20 \%$ by gases in the year 2030 . However, because the past is not necessarily a good indicator of the future, we have generated two alternative cases that show other scenarios of the future energy mix. Future research will compare the present Asia Pacific results to other regions of the world. Based on a preliminary investigation of the historical energy mixes of major consuming regions such as North America and Europe, it is evident that the Asia Pacific has been slower to decarbonize due to its heavy reliance on solid fuels.

4

Results of this study can be used to assess challenges and opportunities in the Asia Pacific as population, income, and energy demand continue to increase. As natural gas is estimated to be abundant, this presents significant opportunities for governments and corporations who have the means and will to increase natural gas use.

(2)




\section{References}

[1] Apergis N, Payne JE. Natural gas consumption and economic growth: A panel investigation of 67 countries. Applied Energy 2010; 87(8): 2759-2763.

[2] Aguilera RF, Ripple RD. Using size distribution analysis to forecast natural gas resources in Asia Pacific. Applied Energy 2011; 88(12): 4607-4620.

[3] British Petroleum. Statistical Review of World Energy. British Petroleum, London, UK; 2010.

[4] United Nations Population Division. World Population Prospects; 2010. http://esa.un.org/unpp/

[5] Aguilera RF, Aguilera R. Assessing the past, present, and near future of the global energy market. SPE paper 102215 presented at SPE Annual Technical Conference and Exhibition, Anaheim, California, United States, 11-14 November, 2007.

[6] Fisher JC, Pry RH. A simple solution model of technological change. Report 70_C-215. General Electric Company, Research and Development Center. New York; 1970 .

[7] Marchetti C, Nakicenovic N. The dynamics of energy systems and the logistic substitution model. RR-79-13. International Institute for Applied Systems Analysis (IIASA) Publications. Laxenburg, Austria; 1979.

[8] Hefner III RA. The age of energy gases in the new millennium. The GHK Company, Oklahoma City. Based on presentation at $10^{\text {th }}$ Repsol-Harvard Seminar on Energy Policy in Madrid, Spain; June 1999, and the SPE Gas Technology Symposium in Calgary, Canada; April 2002.

[9] Grubler A. Energy transitions. In: Cleveland CJ, editor. Encyclopedia of Earth, Washington DC: Environmental Information Coalition, National Council for Science and the Environment; 2008. 
[10] Grubler A, Nakicenovic N, Victor DG. Dynamics of energy technologies and global change.

Energy Policy 1999; 27(5): 247-280.

[11] Ausubel JH, Sladovich HE. Technology and Environment. National Academy Press, Washington DC; 1989.

[12] Grubler A. Transitions in Energy Use. Encyclopedia of Energy 2004; 6: 163-177.

[13] United Nations. World Energy Supplies in Selected Years 1929-1950. Statistical Papers Series J No. 1. United Nations, New York; 1952.

[14] Putnam PC. Energy in the Future. Van Nostrand, Princeton; 1953.

[15] Darmstadter J, Teitelbaum P, Polach J. Energy in the World Economy. John Hopkins, Baltimore; 1971.

[16] Grubler A. Technology and Global Change. Cambridge University Press, United Kingdom; 1998.

[17] International Energy Agency. World Energy Outlook. Paris, France: Organization for Economic Cooperation and Development; 2011.

[18] British Petroleum. BP Energy Outlook 2030. British Petroleum, London, UK; 2011.

[19] Shafiee S, Topal E. A long-term view of worldwide fossil fuel prices. Applied Energy 2010; 87(3): 988-1000.

[20] United States Geological Survey. World Petroleum Assessment. CD-ROM; 2000.

[21] Ahlbrandt TS, McCabe PJ. Global petroleum resources: A view to the future. Geotimes 2002; 47(11): 14-18.

[22] Lund PD. Fast market penetration of energy technologies in retrospect with application to clean energy futures. Applied Energy 2010; 87(11): 3575-3583. 
2

3

4 5

6

10

[23] Thiam DR, Benders RMJ, Moll HC. Modeling the transition towards a sustainable energy production in developing nations. Applied Energy 2012; 94: 98-108.

[24] Marchetti C. Nuclear plants and nuclear niches. Nuclear Science Engineering 1985; 90 : 521-526.

[25] Hefner III RA. The age of energy gases: China's opportunity for global energy leadership. The GHK Company, Oklahoma City, United States; 2007.

[26] Zhang Z. Asian energy and environmental policy: promoting growth while preserving the environment. Energy Policy 2008; 36(10): 3905-3924. 


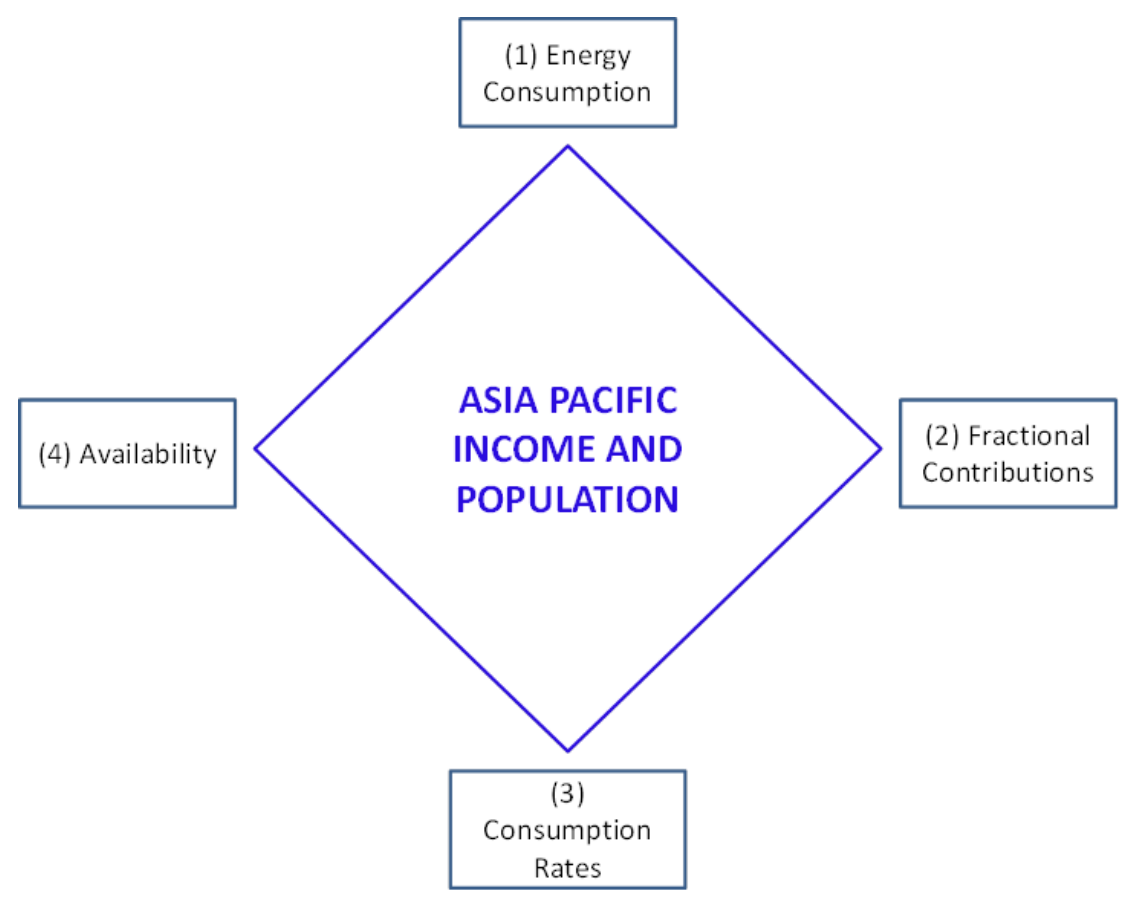

Fig. 1. Diagram showing procedure used to assess the Asia Pacific region. 
100$$
1
$$

1965
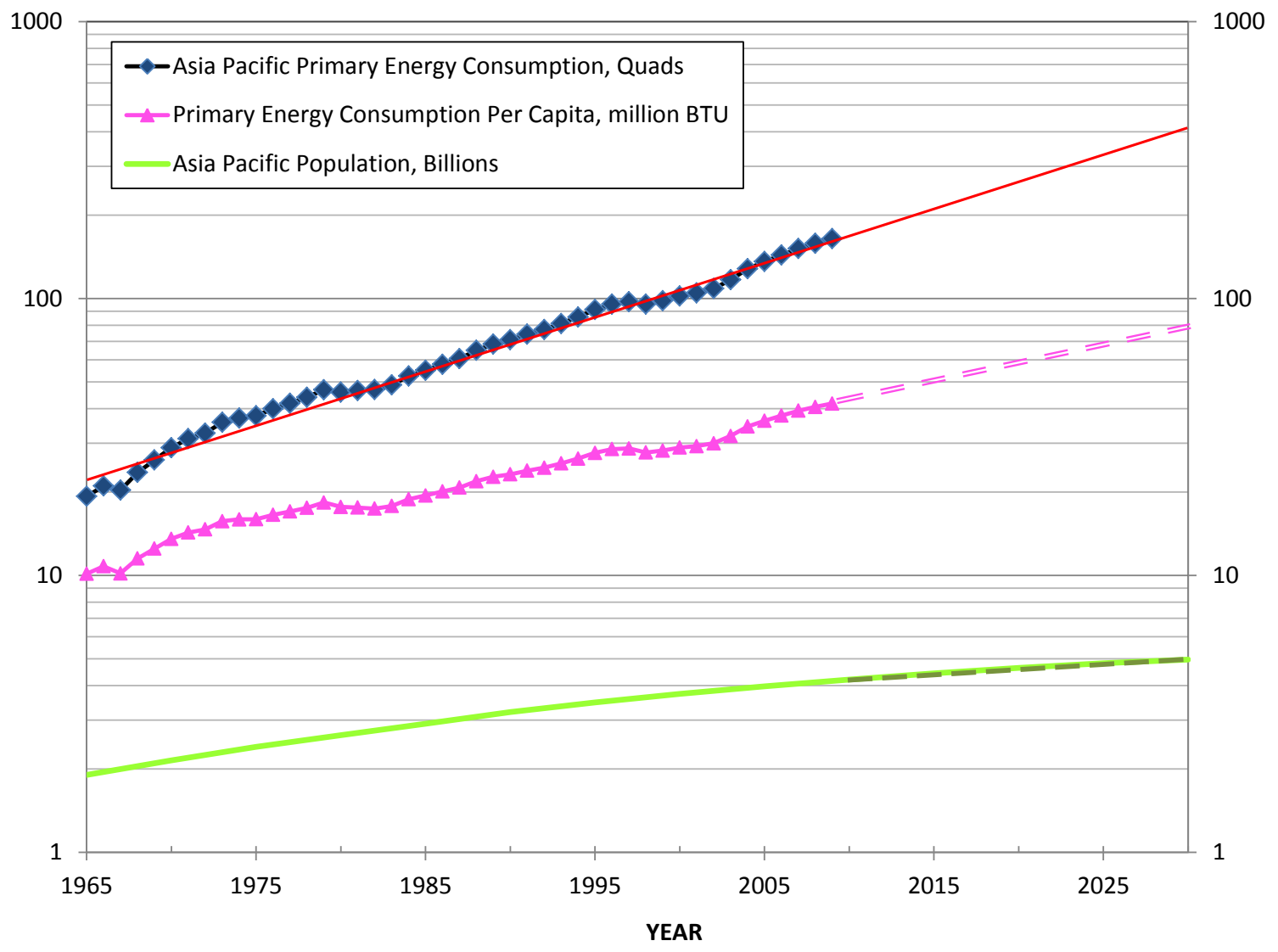

Fig. 2. Asia Pacific population and primary energy consumption. 


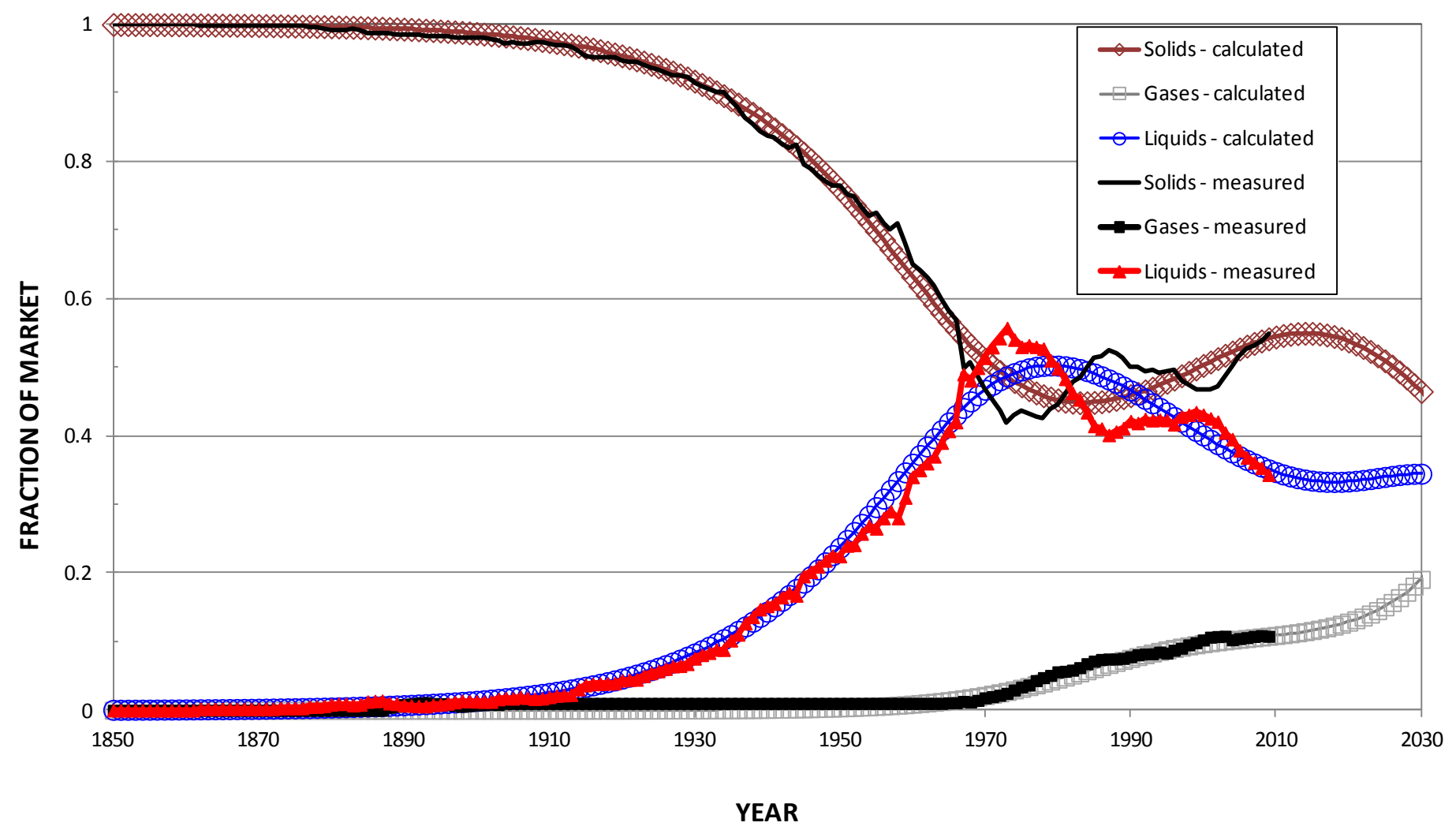

Fig. 3. Asia Pacific primary energy substitution curves including solids, gases and liquids - reference case from the GEM model. 


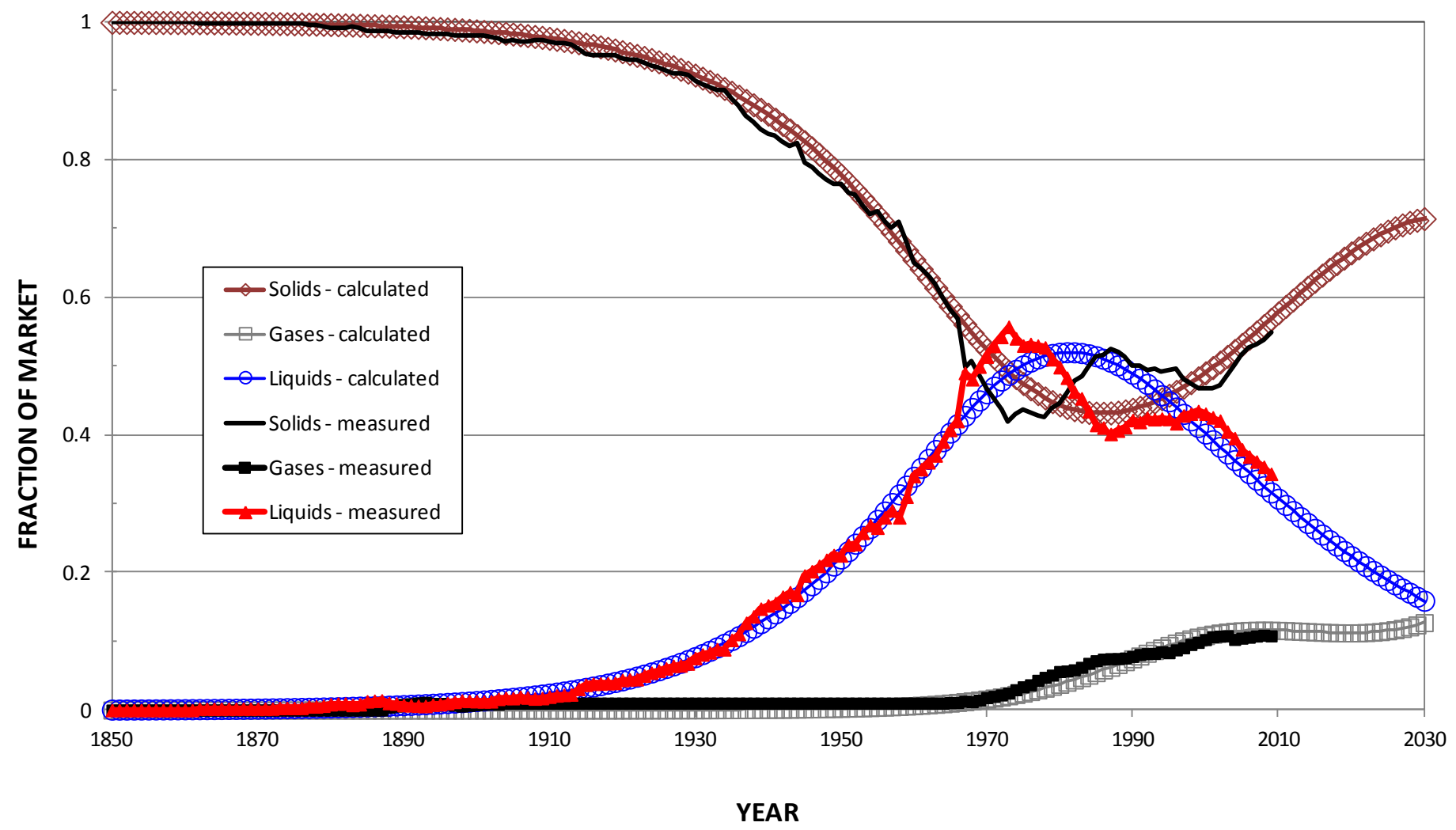

Fig. 4. Asia Pacific primary energy substitution curves including solids, gases and liquids - alternative case 1 from the GEM model. 


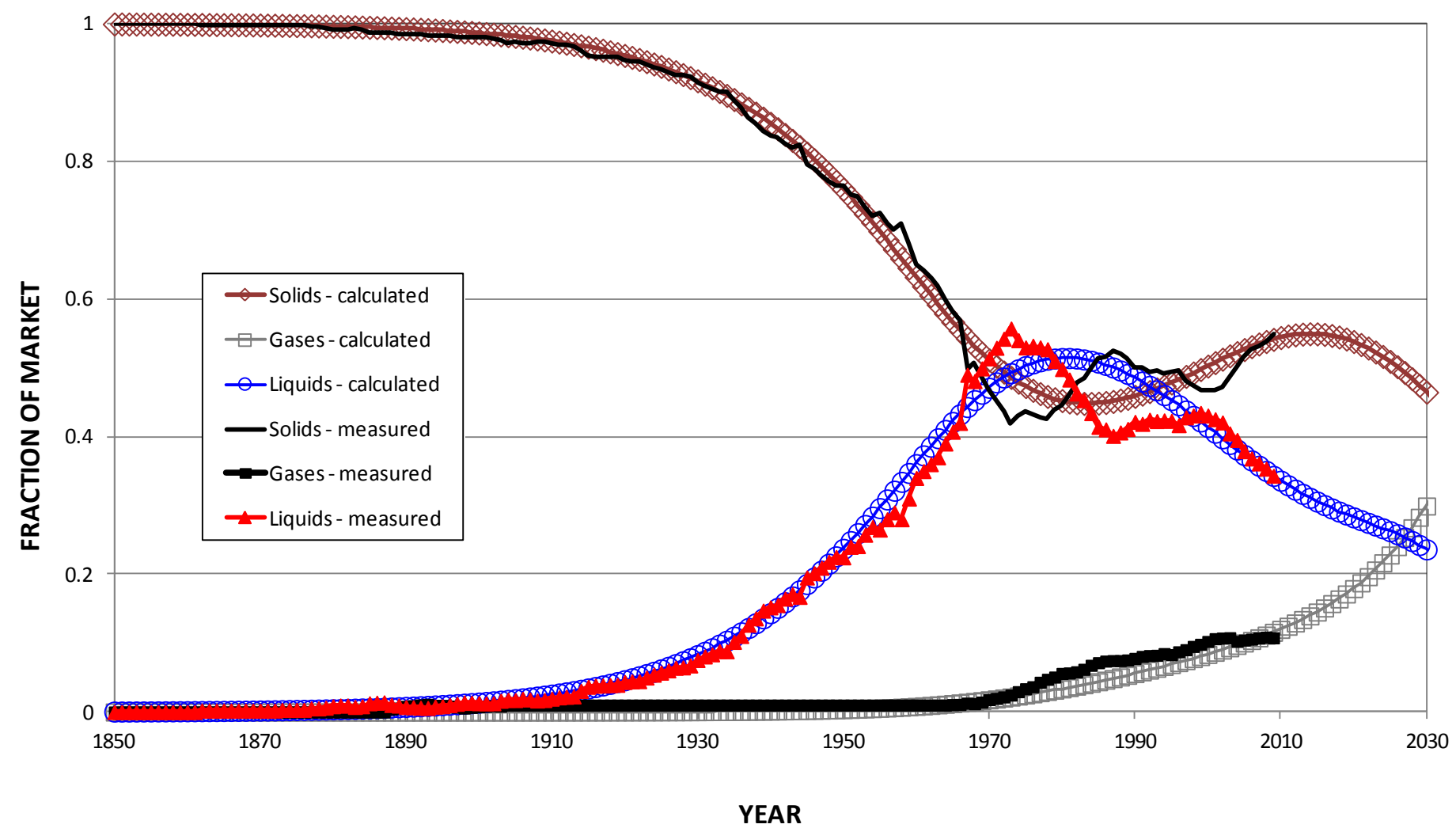

Fig. 5. Asia Pacific primary energy substitution curves including solids, gases and liquids - alternative case 2 from the GEM model. 


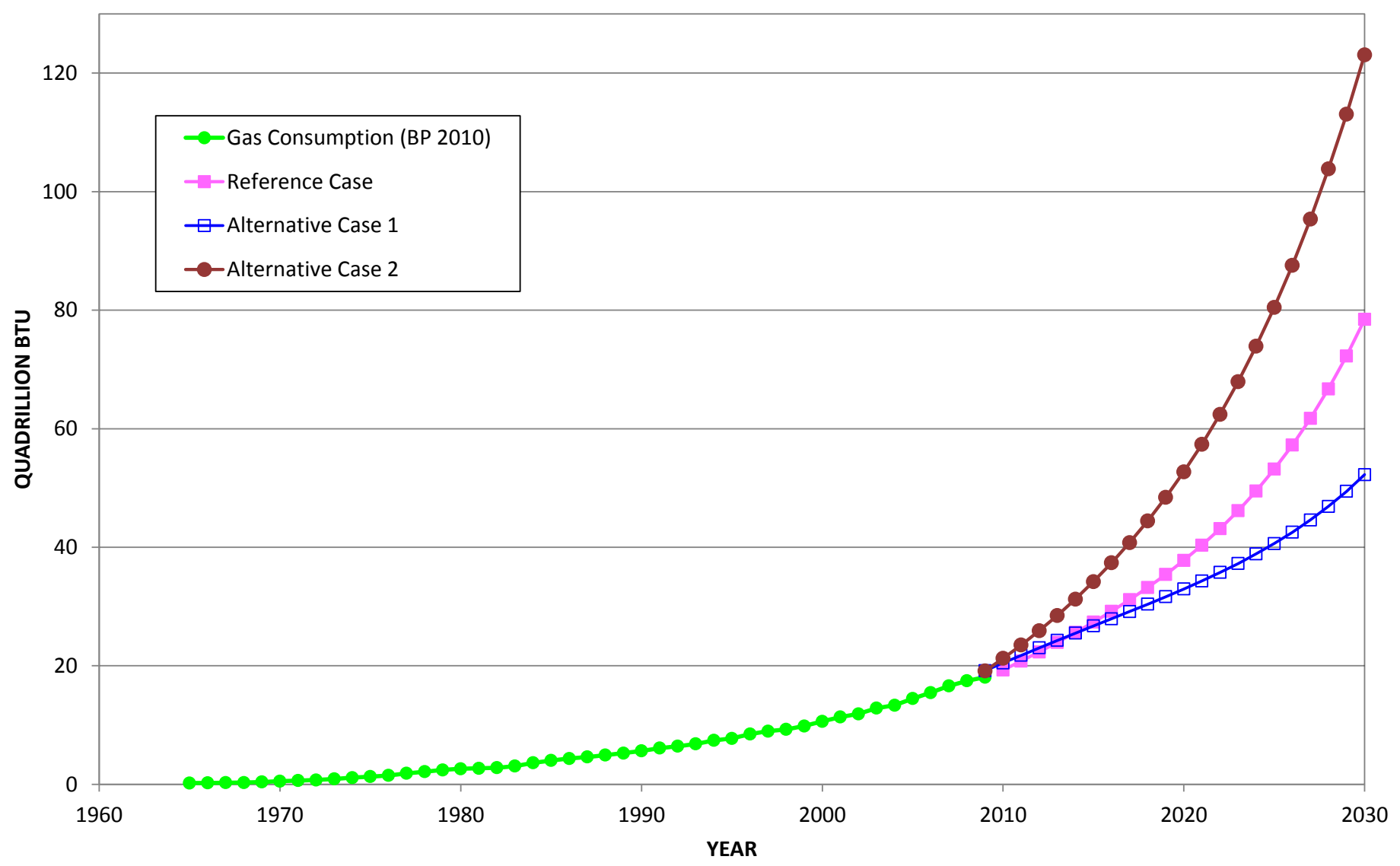

Fig. 6. Reference and alternative case forecasts for consumption of gases in the Asia Pacific. 


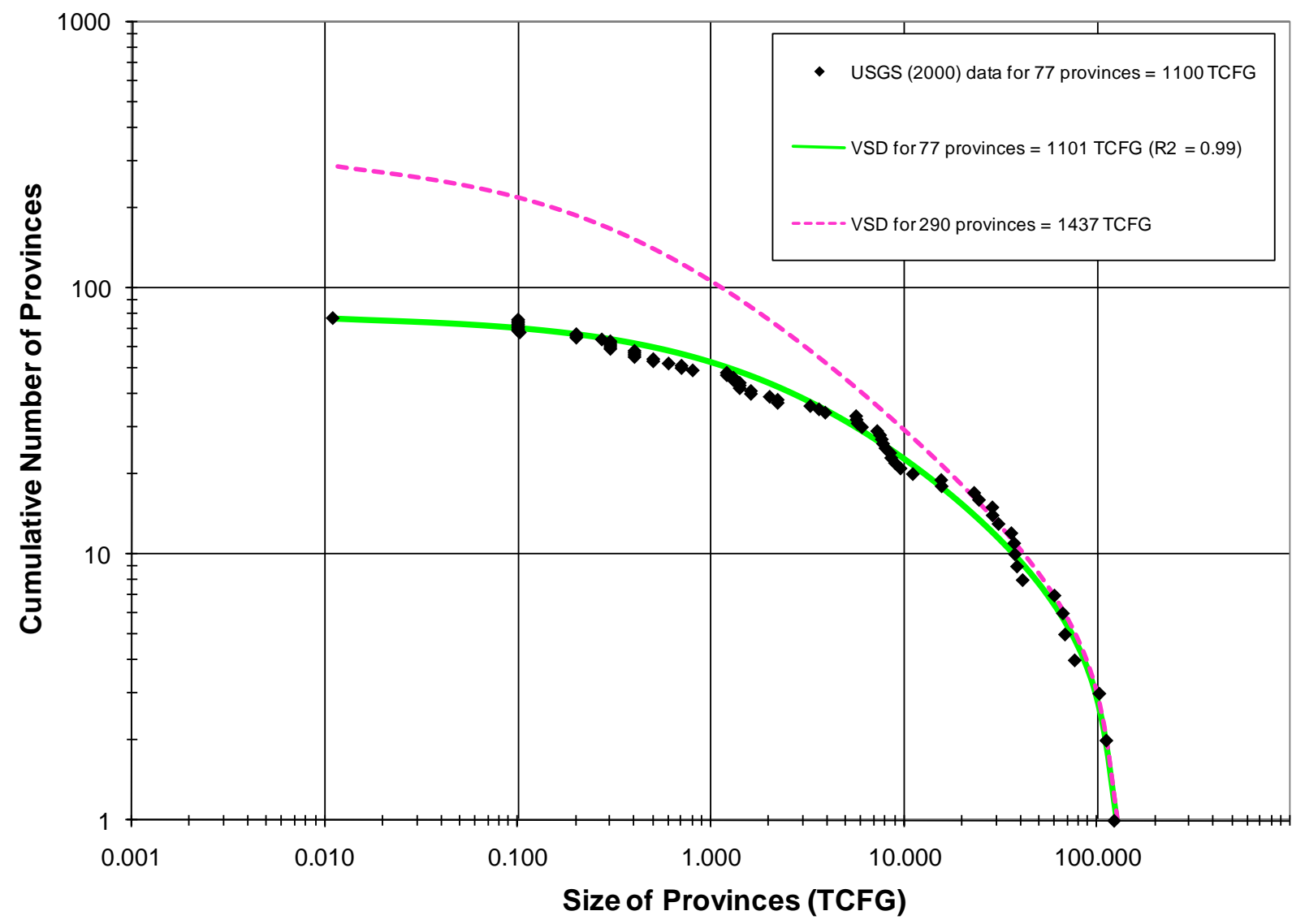

Fig. 7. Asia Pacific natural gas endowment as calculated by [2] and [20]. 


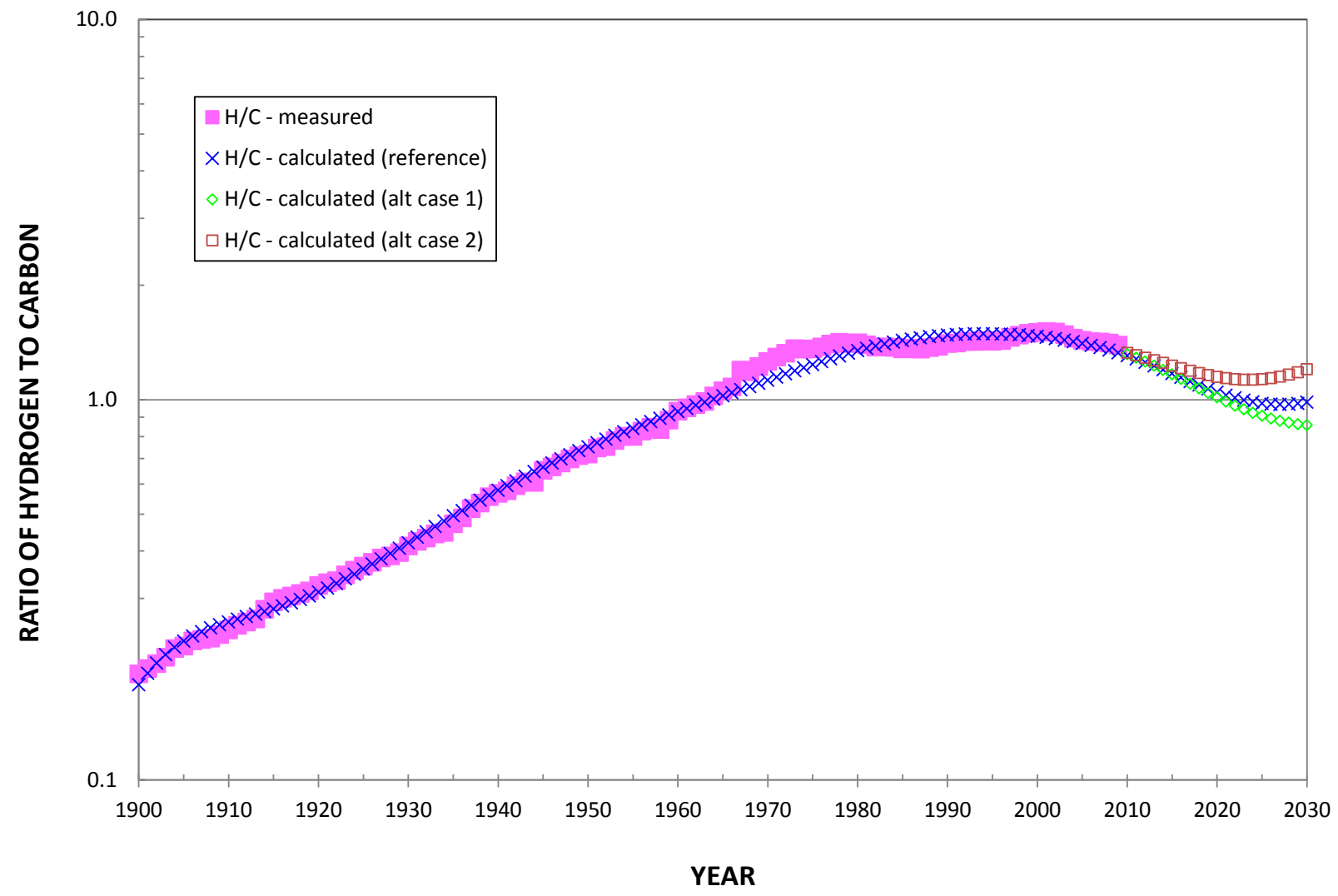

Fig. 8. Asia Pacific hydrogen to carbon (H/C) ratio (a proxy for environmental quality). 